\title{
Alterações morfológicas e alocação de biomassa em plantas jovens de espécies florestais sob diferentes condições de sombreamento ${ }^{1}$
}

\author{
Morphologic alterations and biomass allocation in young plants of forestry species \\ under different conditions of shading \\ Silvia Mara Zanela Almeida ${ }^{2}$ Angela Maria Soares ${ }^{3}$ Evaristo Mauro de Castro ${ }^{4}$ \\ Carlos Vinício Vieira ${ }^{5}$ Evandro Bordignon Gajego ${ }^{6}$
}

\section{RESUMO}

A seleção de espécies nativas elou exóticas para recuperação de ambientes degradados ou alterados pode ser baseada no potencial de aclimatação das espécies a diferentes níveis de luminosidade. Nesse contexto, o objetivo deste estudo foi avaliar o efeito do sombreamento $(0 \%, 30 \%$ e $50 \%$ de interceptação da radiação solar incidente) no crescimento, na alocação de biomassa e nos teores de clorofila total de plantas jovens de quatro espécies florestais de diferentes grupos ecológicos: Maclura tinctoria (L.) D. Don ex Steud. (moreira), Senna macranthera (Collad.) Irwin et Barn. (fedegoso), Hymenaea courbaril L. var. stilbocarpa (Hayne) Lee et Lang. (jatobá) e Acacia mangium Willd. (acácia). Os maiores teores de clorofila total foram observados em condições sombreadas, para todas as espécies. A espécie clímax exigente em luz (moreira), apresentou os maiores resultados de crescimento. Em condições de pleno sol, a espécie pioneira (acácia) alocou mais biomassa em folhas enquanto que a espécie clímax exigente em luz (moreira) produziu mais raízes. Estas observações evidenciam o potencial de aclimatação a diferentes condições de disponibilidade de irradiação, que deve ser considerado em programas de recuperação de ambientes degradados e manejo de áreas naturais.

Palavras-chave: revegetação, crescimento, sombreamento, alocação de biomassa.

\begin{abstract}
The selection of native and/or exotic species for recovery of degraded or perturbed environment can be associated with the acclimatation potential of species in different conditions of shading. In this context, the objective of this research was to evaluate the effect of shading $(0 \%$, $30 \%$ and $50 \%$ of interception of the incident solar radiation) on growth, biomass allocation and chlorophyll levels in young plants of forestry species from different ecological groups: Maclura tinctoria (L.) D. Don ex Steud. (moreira), Senna macranthera (Collad.) Irwin et Barn. (fedegoso), Hymenaea courbaril L. var. stilbocarpa (Hayne) Lee et Lang. (jatobá) $e$ Acacia mangium Willd. (acácia). The results obtained showed that the higher chlorophyll levels were observed in shaded conditions for all species. The climax lighting demanding specie (moreira) showed the highest growth. In sunny conditions, the pioneer species (acacia) produced more leaves while the climax light demanding species (moreira) produced more roots. These observations indicated that these species are capable of acclimation to different conditions of radiation availability, a result that should be considered in regeneration programs of degraded environment and management of natural areas.
\end{abstract}

Key words: revegetation, growth, shading, biomass alocation.

${ }^{1}$ Parte da dissertação do primeiro autor, apresentada à Universidade Federal de Lavras (UFLA).

${ }^{2}$ Bacharel em Ciências Biológicas, MSc, Autônoma, Rua São Gerônimo, 675-D, Bairro Esplanada, 89812-190, Chapecó/SC. Email: smzanela@yahoo.com.br. Autor para correspondência.

${ }^{3}$ Professora Adjunta, Doutora, Setor de Fisiologia Vegetal, Departamento de Biologia, UFLA, CP 37, 37200-000, Lavras, MG.

E-mail: amsoares@ufla.br.

${ }^{4}$ Professor Auxiliar, Doutor, Setor de Fisiologia Vegetal, Departamento de Biologia, UFLA. E-mail: emcastro@ufla.br.

${ }^{5}$ Graduando em Agronomia, Setor de Fisiologia Vegetal, Departamento de Biologia, UFLA.

${ }^{6}$ Graduando em Agronomia, Setor de Fisiologia Vegetal, Departamento de Biologia, UFLA. 


\section{INTRODUÇÃO}

Alguns estudos têm evidenciado a plasticidade fisiológica de espécies em relação à radiação fotossintéticamente ativa disponível, por meio de avaliações de crescimento inicial em relação a diferentes níveis de sombreamento. Tais estudos permitem apresentar propostas para a recolonização de áreas degradadas em diferentes graus e recuperação de ambientes degradados. Apesar desses esforços, o número de informações ainda é insuficiente, em decorrência do grande número de espécies e variáveis ambientais envolvidas, necessitando o desenvolvimento de estudos sobre a ecofisiologia de espécies potenciais, nativas ou exóticas, para os processos de regeneração, formação de matas ciliares e recuperação de ambientes perturbados devido à ação antrópica ou a causas naturais.

$\mathrm{O}$ crescimento das plantas pode refletir a habilidade de adaptação das espécies às condições de radiação do ambiente em que estão se desenvolvendo. Geralmente as características de crescimento são utilizadas para inferir o grau de tolerância ou de intolerância das espécies à baixa disponibilidade de luz (SCALON et al., 2002). O sucesso na adaptação de uma espécie a ambientes com baixa ou alta radiação está associado a eficiência na partição dos fotoassimilados para diferentes partes da planta e na rapidez em ajustar variáveis morfofisiológicas no sentido de maximizar a aquisição dos recursos primários (DIAS-FILHO, 1997). Assim, postula-se que as espécies características de estádios finais de sucessão apresentam um crescimento mais lento em relação às dos estádios iniciais e intermediários (BAZZAZ, 1979).

Estudos de crescimento e respostas fotossintéticas para sombra em um grupo de plantas jovens de quatro espécies florestais constituído por espécies tolerantes, de tolerância intermediária e intolerantes à sombra, mostraram que as características de crescimento responderam significativamente aos tratamentos de 79 e $89 \%$ de sombreamento, sendo que houve uma menor biomassa total para todas as espécies nestes tratamentos e um aumento na área foliar específica (GRONINGER et al., 1996). Em estudo de crescimento inicial de Euterpe edulis em diferentes condições de sombreamento, foi observado que as plantas sob forte sombreamento ( $2 \%$ ou $6 \%$ da luz solar direta) apresentaram em relação às plantas sob maior nível de luz, menor biomassa, menores taxas de crescimento, menor razão raiz/parte aérea e menor razão clorofila a/b (NAKAZONO et al., 2001). Para a espécie Solanum crinitum Lam. (pioneira), a proporção de biomassa alocada nas folhas foi semelhante entre as plantas desenvolvidas sob altos $\left(800-1000 \mathrm{mmol} \mathrm{m}^{-2} \mathrm{~s}^{-1}\right)$ e baixos $\left(200-350 \mathrm{mmol} \mathrm{m}^{-2} \mathrm{~s}^{-1}\right)$ regimes de luminosidade, enquanto nas raízes foi maior em plantas cultivadas sob alta luminosidade, nos caules e pecíolos, foi maior em plantas cultivadas em baixa luminosidade (DIAS-FILHO, 1997).

Para classificar as espécies tropicais quanto a sua estratégia sucessional, o sistema de classificação de SWAINE \& WHITMORE (1988) tem sido considerado como o mais próximo das visões modernas da dinâmica de florestas tropicais (OLIVEIRA-FILHO et al., 1994). O sistema considera duas categorias: espécies pioneiras $(\mathrm{P})$ e espécies clímax (C), sendo as espécies clímax classificadas em função de uma escala dependente da intensidade luminosa exigida para o crescimento pelos imaturos da espécie. Essa escala divide-se em espécies clímax tolerante à sombra (CS) e clímax exigente em luz (CL). As espécies pioneiras surgem após perturbações que expõem o solo à luz. As espécies clímax exigentes em luz também têm este comportamento, porém vivem mais que as pioneiras e, freqüentemente, tornam-se grandes árvores emergentes. As espécies clímax tolerantes à sombra sobrevivem na sombra, onde crescem lentamente até atingir o dossel (BOTELHO et al., 1995).

O objetivo deste trabalho foi avaliar o efeito do sombreamento no crescimento inicial e nos teores de clorofila em plantas jovens de três espécies nativas: Maclura tinctoria (L.) D. Don ex Steud. (clímax exigente em luz), Senna macranthera (Collad.) Irwin et Barn. (pioneira) e Hymenaea courbaril L. var. stilbocarpa (Hayne) Lee et Lang. (clímax tolerante a sombra) e uma espécie exótica pioneira Acácia mangium Willd.

\section{MATERIAL E MÉTODOS}

O presente estudo foi conduzido no período de dezembro de 1999 a março de 2001, na área experimental do Setor de Fisiologia Vegetal, Departamento de Biologia da Universidade Federal de Lavras (UFLA), no município de Lavras, localizado na região sul do Estado de Minas Gerais, a $918 \mathrm{~m}$ de altitude, latitude $21^{\circ} 14^{\prime} \mathrm{S}$ e longitude $45^{\circ} 00^{\prime} \mathrm{W}$ GRW. A média anual de temperatura do ar é de $19,4^{\circ} \mathrm{C}$ com médias anuais de temperatura do ar máxima e mínima, respectivamente, de $26,1^{\circ} \mathrm{C}$ e $14,8^{\circ} \mathrm{C}$, e precipitação total anual média de $1529,7 \mathrm{~mm}$ (BRASIL, 1992). Segundo a classificação climática de KÖPPEN (1948), o clima regional é do tipo Cwa, com características de Cwb, apresentando duas estações bem definidas: seca, de abril a setembro, e chuvosa, de outubro a março. 
As sementes utilizadas para obtenção das mudas de moreira foram coletadas, em dezembro de 1999, de plantas matrizes localizadas no campus da Universidade Federal de Lavras, MG. Para obtenção das demais mudas, as sementes utilizadas foram fornecidas pelo Laboratório de Sementes Florestais do Departamento de Ciências Florestais da Universidade Federal de Lavras, MG em fevereiro de 2000. As sementes de jatobá, acácia e fedegoso passaram por processos de quebra de dormência segundo recomendação de DAVIDE et al. (1995).

Estas espécies foram selecionadas em função do grupo sucessional, do habitat de origem e do interesse para programas de reflorestamento de mata ciliar na região do Alto e Médio Rio Grande e/ou regeneração de ambientes degradados. Tais espécies são de ambientes mésicos e têm apresentando bons resultados em plantios experimentais às margens do reservatório de Camargos/Itutinga - MG (BOTELHO et al., 1995).

Todas as sementes foram colocadas para germinar em bandejas contendo areia lavada, cobertas com vermiculita. Após germinarem e atingirem o estádio de um par de folhas, foram transplantadas para recipientes com $0,50 \mathrm{~m}$ de altura e $0,20 \mathrm{~m}$ de diâmetro, contendo aproximadamente 15 litros de substrato composto de uma mistura de Latossolo Vermelho Escuro (LVE), distrófico, textura argilosa, areia e esterco bovino na proporção 3:1:1. A partir da análise mineralógica, foram incorporados ao substrato superfosfato simples na dosagem de $5,0 \mathrm{~kg} \mathrm{~m}^{-3}$ e cloreto de potássio na dosagem de $2,5 \mathrm{~kg} \mathrm{~m}^{-3}$. As plantas permaneceram por 7 meses sob telado de sombrite com $30 \%$ de interceptação da radiação solar. Após esse período, foram submetidas a três diferentes tratamentos de sombreamento: $0 \%, 30 \%$ e $50 \%$ de interceptação da radiação solar incidente. O nível de $0 \%$ foi obtido colocando as plantas em uma área aberta e livre de sombreamentos, enquanto que os níveis de $30 \%$ e $50 \%$ foram obtidos com a utilização de telas de náilon, conhecidas comercialmente como telas sombrite, conforme especificações do fabricante, em área de viveiro. Cada tratamento foi constituído de 16 plantas distribuídas ao acaso em um esquema de 4 x 4 (4 fileiras de 4 plantas cada), sendo que cada planta constituía uma repetição. Cada característica avaliada teve seu número peculiar de repetições de acordo com a metodologia empregada nas análises em questão.

A determinação do teor de clorofila foi realizada no final do período experimental em seis plantas por tratamento, tomadas aleatoriamente pela utilização de sorteio. De cada planta, foram retiradas três folhas completamente expandidas, localizadas entre o ápice, o meio e a base da planta, que foram imediatamente acondicionadas em papel alumínio e colocadas em caixa de isopor com gelo. A quantificação das clorofilas a, b e total foi realizada segundo o método proposto por ARNON (1949).

O crescimento das plantas foi avaliado nas 16 plantas de cada tratamento, com base nas seguintes características: comprimento e diâmetro do caule, matéria seca de folhas, caule e raízes, em oito plantas de cada tratamento. O comprimento do caule foi considerado desde o colo até o ápice de cada planta e o diâmetro tomado a $3 \mathrm{~cm}$ do solo.

No final do experimento, foram sorteadas oito plantas, as quais foram separadas em folhas, caule e raízes. Todo material foi acondicionado em sacos de papel e colocados em estufa com circulação forçada de ar, a aproximadamente $70^{\circ} \mathrm{C}$, durante 72 horas. Após a secagem, o material foi pesado para quantificar a distribuição da biomassa.

Todas as características foram avaliadas seguindo um delineamento experimental inteiramente casualizado. Foi realizada análise de variância, sendo que as médias foram comparadas pelo teste de Tukey, em nível de $5 \%$ de probabilidade de erro.

\section{RESULTADOS E DISCUSSÃO}

A espécie clímax exigente em luz, moreira, apresentou os maiores teores de clorofila total quando comparada com as demais espécies (Tabela 1). No tratamento de $50 \%$ de sombreamento, não houve diferença entre a moreira, o jatobá e o fedegoso; somente a acácia apresentou os menores teores de clorofila total em todos os tratamentos e média quando comparada com as demais espécies. Ao se comparar as espécies isoladamente, é possível observar que no tratamento de $50 \%$ de sombreamento, as espécies jatobá e fedegoso acumularam maiores teores de clorofila total, e a moreira nos tratamentos $30 \%$ e $50 \%$ de sombreamento. Para a pioneira acácia, não foi observada diferença entre os tratamentos $(\mathrm{P}<0,05)$ (Tabela 1). Este maior acúmulo de clorofila nos níveis de maior sombreamento pode ser devido a compensação da espécie a menor quantidade de radiação disponível. Os resultados são semelhantes aos citados na literatura (ELLSWORTH \& REICH, 1992; MENDES et al., 2001). BOARDMAN (1977) reforça a idéia de que folhas cultivadas sob baixas intensidades de radiação, apresentam maiores teores de clorofilas por unidade de massa.

Quanto à relação entre as clorofilas a e b pode ser observado (Tabela 1) que nos tratamentos a pleno sol e $50 \%$ de sombreamento não houve diferença 
Tabela 1 - Teor de clorofila total e razão clorofila a/b em plantas jovens de quatro espécies florestais submetidas a diferentes níveis de sombreamento.

\begin{tabular}{cccc}
\hline \multirow{2}{*}{ Espécie } & Sombreamentc & $\begin{array}{c}\text { Clorofila Total } \\
(\mathrm{mg} / \mathrm{g} \mathrm{MF})\end{array}$ & Razão Clorofila a/b \\
\hline \multirow{5}{*}{ Moreira } & $0 \%$ & $2,19 \mathrm{Ab}$ & $1,57 \mathrm{Aa}$ \\
& $30 \%$ & $3,15 \mathrm{Aa}$ & $1,70 \mathrm{BCa}$ \\
& $50 \%$ & $3,38 \mathrm{Aa}$ & $2,10 \mathrm{Aa}$ \\
\cline { 2 - 4 } & Média & $2,91 \mathrm{~A}$ & $1,79 \mathrm{~B}$ \\
\cline { 2 - 4 } Jatobá & $0 \%$ & $1,56 \mathrm{ABb}$ & $2,05 \mathrm{Aa}$ \\
& $30 \%$ & $2,04 \mathrm{Bb}$ & $2,35 \mathrm{Aa}$ \\
& $50 \%$ & $2,96 \mathrm{Aa}$ & $2,11 \mathrm{Aa}$ \\
\cline { 2 - 4 } & Média & $2,19 \mathrm{~B}$ & $2,17 \mathrm{~A}$ \\
\cline { 2 - 4 } Fedegoso & $0 \%$ & $1,66 \mathrm{ABb}$ & $1,87 \mathrm{Aa}$ \\
& $30 \%$ & $1,99 \mathrm{Bb}$ & $2,22 \mathrm{ABa}$ \\
& $50 \%$ & $3,25 \mathrm{Aa}$ & $1,70 \mathrm{Aa}$ \\
\cline { 2 - 4 } & Média & $2,30 \mathrm{~B}$ & $1,93 \mathrm{AB}$ \\
\cline { 2 - 4 } & $0 \%$ & $1,05 \mathrm{Ba}$ & $2,14 \mathrm{Aa}$ \\
& $30 \%$ & $1,52 \mathrm{Ba}$ & $1,36 \mathrm{Cb}$ \\
Acácia & $50 \%$ & $1,71 \mathrm{Ba}$ & $1,60 \mathrm{Aab}$ \\
\cline { 2 - 4 } & Média & $1,43 \mathrm{C}$ & \\
\hline & & & $1,70 \mathrm{~B}$ \\
\hline
\end{tabular}

* Médias não seguidas pelas mesmas letras, maiúsculas comparando entre espécies e minúsculas comparando dentro de espécies, diferem entre si pelo teste de Tukey, em nível de 5\% de probabilidade de erro.

entre as espécies. No tratamento com $30 \%$ de sombreamento e na média geral, pode-se observar que a espécie clímax - jatobá - tolerante à sombra apresentou uma maior relação clorofila $\mathrm{a} / \mathrm{b} \mathrm{em}$ comparação com as demais espécies, exceto para a espécie fedegoso, da qual não diferiu estatisticamente. Apenas a acácia apresentou diferenças significativas entre os tratamentos, sendo a maior relação clorofila $a / b$ encontrada nas plantas cultivadas a pleno sol. A proporção entre clorofilas a e b, de uma maneira geral tende a diminuir com a redução da intensidade luminosa (BOARDMAN, 1977; KOZLOWSKI et al., 1991), devido a uma maior proporção relativa de clorofila $b$ em ambiente sombreado. Este aumento da clorofila b em ambientes sombreados está associado a sua degradação ser mais lenta do que a clorofila a (ENGEL \& POGGIANI, 1991). Alguns estudos, entretanto, mostraram maiores valores da relação clorofila $\mathrm{a} / \mathrm{b}$ em condições sombreadas (CASTRO et al., 1996; LEE et al., 2000). Entretanto para a espécie Myrtus communis não foi encontrada diferença na relação clorofila a/b em plantas cultivadas a pleno sol ou 30\% de irradiância (MENDES et al., 2001).

As diferentes condições de sombreamento impostas às plantas levaram a diferenças em altura e diâmetro do coleto (Tabela 2). Em relação à altura, as
Tabela 2 - Altura e diâmetro do coleto em plantas jovens de quatro espécies florestais submetidas a diferentes níveis de sombreamento.

\begin{tabular}{cccc}
\hline \multirow{2}{*}{ Espécie } & Sombreamento & Altura $(\mathrm{cm})$ & $\begin{array}{c}\text { Diâmetro } \\
(\mathrm{mm})\end{array}$ \\
\hline \multirow{3}{*}{ Moreira } & $0 \%$ & $76,38 \mathrm{ABc}$ & $15,94 \mathrm{Aa}$ \\
& $30 \%$ & $103,38 \mathrm{Ab}$ & $14,37 \mathrm{Aa}$ \\
& $50 \%$ & $125,00 \mathrm{Aa}$ & $15,38 \mathrm{Aa}$ \\
\cline { 2 - 4 } & Média & $101,58 \mathrm{~A}$ & $15,23 \mathrm{~A}$ \\
\cline { 2 - 4 } Jatobá & $0 \%$ & $55,19 \mathrm{Ba}$ & $10,75 \mathrm{Ba}$ \\
& $30 \%$ & $63,25 \mathrm{Ba}$ & $11,94 \mathrm{Aa}$ \\
& $50 \%$ & $67,69 \mathrm{Ba}$ & $12,31 \mathrm{Ba}$ \\
\cline { 2 - 4 } & Média & $62,04 \mathrm{~B}$ & $11,67 \mathrm{~B}$ \\
\cline { 2 - 4 } Fedegoso & $0 \%$ & $81,13 \mathrm{Ab}$ & $10,38 \mathrm{Bb}$ \\
& $30 \%$ & $109,88 \mathrm{Aa}$ & $13,56 \mathrm{Aa}$ \\
& $50 \%$ & $112,50 \mathrm{Aa}$ & $13,06 \mathrm{ABa}$ \\
\cline { 2 - 4 } & Média & $101,17 \mathrm{~A}$ & $12,33 \mathrm{~B}$ \\
\cline { 2 - 4 } & $0 \%$ & $59,50 \mathrm{ABa}$ & $11,56 \mathrm{Ba}$ \\
& $30 \%$ & $65,63 \mathrm{Ba}$ & $9,25 \mathrm{Bb}$ \\
& $50 \%$ & $53,00 \mathrm{Ba}$ & $7,56 \mathrm{Cb}$ \\
\hline \multirow{4}{*}{ Acácia } & & $59,38 \mathrm{~B}$ & $9,45 \mathrm{C}$ \\
& & &
\end{tabular}

*Médias não seguidas pelas mesmas letras, maiúsculas comparando entre espécies e minúsculas comparando dentro de espécies, diferem entre si pelo teste de Tukey, em nível de 5\% de probabilidade de erro.

plantas de moreira e fedegoso expostas a condições sombreadas exibiram maior crescimento em relação à condição de pleno sol. Para o jatobá e a acácia, não houve diferenças entre tratamentos. Ao comparar as espécies, pode-se observar que a moreira e o fedegoso apresentaram maiores valores em alturas na média em todos os tratamentos em relação as demais espécies (Tabela 2). Os resultados obtidos para moreira e fedegoso concordam com alguns trabalhos na literatura com espécies lenhosas, nas quais a maior altura ocorre em condições sombreadas (MAZZEI et al., 1998; FELFILI et al., 1999; ATROCH et al., 2001). Entretanto, KE \& WERGER (1999), estudando duas espécies de Carvalho, uma sempre verde e uma decídua, observaram maiores valores de alturas nas plantas submetidas a pleno sol.

Quanto ao diâmetro do coleto, as espécies diferiram entre si, sendo que a moreira apresentou os maiores valores, o mesmo ocorrendo nas condições de pleno sol e $50 \%$ de sombreamento. Na condição de $30 \%$ de sombreamento, apenas a acácia diferiu das demais, sendo seu valor menor. Houve um comportamento diferencial das espécies pioneiras. Para acácia, houve uma redução no diâmetro do caule à medida que aumentou o sombreamento, enquanto que o fedegoso apresentou os maiores diâmetros nas 
condições sombreadas. A moreira e o jatobá não apresentaram diferenças significativas nos diferentes tratamentos (Tabela 2). Em estudo com a espécie pioneira Cabralea canjerana em quatro condições de luminosidade, SOUZA-SILVA et al. (1999) também não encontraram diferenças nos diâmetros do coleto a partir dos 10 meses de idade, sendo que aos sete meses de idade estes mesmos autores encontraram maior diâmetro de coleto sob condições de pleno sol. No entanto, outros autores têm verificado a tendência de maiores diâmetros do caule quando as plantas são submetidas a condições sombreadas (MAZZEI et al., 1998; MAZZEI et al., 1999).

Com relação à distribuição de matéria seca total e entre os diversos órgãos da planta, observou-se um comportamento diferencial entre espécies (Tabela 3). Considerando-se as matérias secas de caule, raiz, e matéria seca total, observa-se que a moreira apresentou os maiores valores médios em todos os tratamentos e na média geral, em relação as outras espécies, exceto na condição de $30 \%$ de sombreamento, na qual a matéria seca do caule foi igual a do fedegoso. Com relação ao acúmulo de matéria seca foliar, apenas a acácia destacouse entre as demais espécies. No tratamento com $50 \%$ de sombreamento, as espécies moreira e fedegoso demonstraram melhor performance que as demais (Tabela 3). Para a espécie clímax Quercus robur L., WELANDER \& OTTOSSON (2000) observaram um incremento no acúmulo de matéria seca total com o aumento na disponibilidade de luz. Resultados semelhantes foram obtidos em duas outras espécies de carvalho sob duas condições de luminosidade, com melhor performance das plantas a pleno sol em termos de matéria seca total, de raízes, caules e folhas (KE \& WERGER, 1999). Em relação à matéria seca de caules, nenhuma espécie diferiu nos diferentes tratamentos. Também foi verificado que plantas de moreira e acácia expostas a pleno sol produziram mais matéria seca de raízes e total do que as plantas em condições sombreadas.

A figura 1 mostra que a espécie clímax moreira exigente em luz aloca a maior parte de sua produção de biomassa para as raízes. Esta alocação é mais evidente nas plantas cultivadas a pleno sol. No jatobá e na acácia, os padrões são semelhantes, sendo que, na condição de $30 \%$ de sombreamento, estas plantas investem menos em raízes e mais em caules. $\mathrm{O}$ fedegoso aloca cerca de $40 \%$ de sua biomassa nas raízes sendo que não há uma diferença evidente entre os tratamentos. Indivíduos de uma espécie com sistemas radiculares mais extensos têm uma maior capacidade de aclimatação quando comparados com aqueles com sistemas radiculares menores (CLAUSSEN, 1996).

Uma maior alocação de biomassa para raízes em plantas sob condições de pleno sol também foi observado por DIAS-FILHO (1997) em Solanum crinitum, espécie pioneira, na qual a distribuição de biomassa para as raízes em baixa luminosidade foi reduzida de $15 \%$ em relação a plantas sob pleno sol. Como sugerido por THOMPSON et al. (1992) e WALTERS et al. (1993), esta menor distribuição para

Tabela 3 - Matéria seca das folhas (MSFol), caule (MSCa), raízes (MSR), e total (MST) em plantas jovens de quatro espécies florestais submetidas a diferentes níveis de sombreamento.

\begin{tabular}{|c|c|c|c|c|c|}
\hline Espécie & Sombreamento & MSFol (g) & $\operatorname{MSCa}(\mathrm{g})$ & $\operatorname{MSR}(g)$ & $\operatorname{MST}(\mathrm{g})$ \\
\hline \multirow{4}{*}{ Moreira } & $0 \%$ & $23,18 \mathrm{Ba}$ & $53,28 \mathrm{Aa}$ & 99,79 Aa & $176,26 \mathrm{Aa}$ \\
\hline & $30 \%$ & $20,95 \mathrm{Aa}$ & $48,58 \mathrm{Aa}$ & $57,11 \mathrm{Ab}$ & $126,64 \mathrm{Ab}$ \\
\hline & $50 \%$ & $23,27 \mathrm{Aa}$ & $61,22 \mathrm{Aa}$ & $49,89 \mathrm{Ab}$ & 134,37 Aab \\
\hline & Média & $22,47 \mathrm{~A}$ & $54,36 \mathrm{~A}$ & $68,93 \mathrm{~A}$ & $145,76 \mathrm{~A}$ \\
\hline \multirow{4}{*}{ Jatobá } & $0 \%$ & $21,19 \mathrm{Ba}$ & $18,14 \mathrm{Ba}$ & $29,37 \mathrm{Ba}$ & $68,70 \mathrm{Ba}$ \\
\hline & $30 \%$ & $23,90 \mathrm{Aa}$ & $20,38 \mathrm{Ba}$ & $18,77 \mathrm{Ba}$ & $63,06 \mathrm{BCa}$ \\
\hline & $50 \%$ & $18,40 \mathrm{ABa}$ & $19,62 \mathrm{Bca}$ & $21,81 \mathrm{ABa}$ & $59,83 \mathrm{BCa}$ \\
\hline & Média & $21,16 \mathrm{~A}$ & $19,38 \mathrm{C}$ & $23,32 \mathrm{~B}$ & $63,86 \mathrm{C}$ \\
\hline \multirow{4}{*}{ Fedegoso } & $0 \%$ & $20,25 \mathrm{Ba}$ & $26,80 \mathrm{Ba}$ & $33,80 \mathrm{Ba}$ & $80,86 \mathrm{Ba}$ \\
\hline & $30 \%$ & $28,62 \mathrm{Aa}$ & $42,10 \mathrm{Aa}$ & $41,19 \mathrm{ABa}$ & $111,91 \mathrm{ABa}$ \\
\hline & $50 \%$ & $22,62 \mathrm{Aa}$ & $36,61 \mathrm{Ba}$ & $32,72 \mathrm{ABa}$ & $91,94 \mathrm{ABa}$ \\
\hline & Média & $23,83 \mathrm{~A}$ & $35,17 \mathrm{~B}$ & $35,90 \mathrm{~B}$ & $94,90 \mathrm{~B}$ \\
\hline \multirow{4}{*}{ Acácia } & $0 \%$ & $49,56 \mathrm{Aa}$ & $22,18 \mathrm{Ba}$ & $43,05 \mathrm{Ba}$ & $114,78 \mathrm{Ba}$ \\
\hline & $30 \%$ & $21,64 \mathrm{Ab}$ & $16,95 \mathrm{Ba}$ & $16,86 \mathrm{Bab}$ & $55,45 \mathrm{Cb}$ \\
\hline & $50 \%$ & $10,74 \mathrm{Bc}$ & $6,53 \mathrm{Ca}$ & $6,32 \mathrm{Bb}$ & $23,58 \mathrm{Cb}$ \\
\hline & Média & $27,31 \mathrm{~A}$ & $15,22 \mathrm{C}$ & $22,08 \mathrm{~B}$ & $64,86 \mathrm{C}$ \\
\hline
\end{tabular}

* Médias não seguidas pelas mesmas letras, maiúsculas comparando entre espécies e minúsculas comparando dentro de espécies, diferem entre si pelo teste de Tukey, em nível de $5 \%$ de probabilidade de erro.

Ciência Rural, v.35, n.1, jan-fev, 2005. 


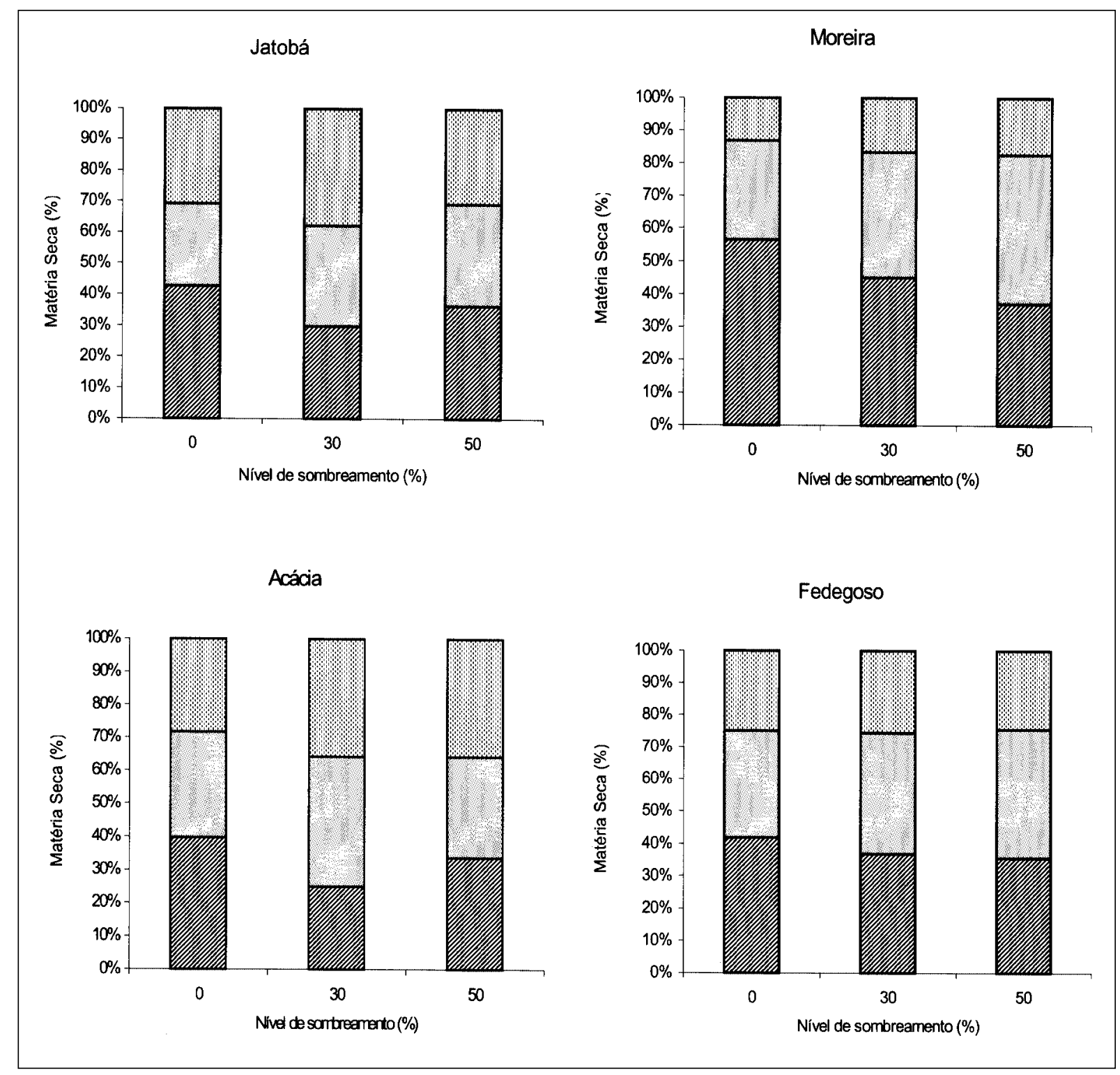

Figura 1 - Distribuição de matéria seca nas raízes ( $\square$ ), caules (四) e folhas (영) em plantas jovens de quatro espécies florestais.

raízes sobre baixas condições de luminosidade provavelmente revela uma resposta a atributos que propiciou um maior ganho de carbono sobre irradiância reduzida, como um aumento na razão de área foliar ou razão de massa foliar, ou que reflita uma estratégia buscando luminosidade como um aumento na altura.

Nas condições em que esse estudo foi desenvolvido, os resultados obtidos evidenciam que espécies de status sucessionais distintos exibem respostas diferenciais em relação às características fisiológicas avaliadas, quando submetidas a diferentes níveis de irradiância. Entretanto, nem sempre essas respostas são associadas ao grupo sucessional da espécie, indicando uma capacidade de aclimatação das espécies a diferentes condições de sombreamento.

\section{REFERÊNCIAS BIBLIOGRÁFICAS}

ARNON, D.I. Cooper enzymes in isolated chloroplasts. Polyphenoloxidase in Beta vulgaris. Plant Physiology, Maryland, v.24, n.1, p.1-15, 1949.

ATROCH, E.M.A.C. et al. Crescimento, teor de clorofilas, distribuição de biomassa e características anatômicas de plantas jovens de Bauhinia forficata Link. submetidas a diferentes condições de sombreamento. Ciência e Agrotecnologia, v. 25, p. $853-862,2001$

Ciência Rural, v.35, n.1, jan-fev, 2005. 
BAZZAZ, F.A. The physiological ecology of plant succession. Annual Review of Ecology and Systematics, Palo Alto, v.10, p.351-371, 1979.

BOARDMAN, N.K. Comparative photosynthesis of sun and shade plants. Annual Review of Plant Physiology, Palo Alto, v.28, p.355-377, 1977.

BOTELHO, S.A. et al. Implantação de mata ciliar. Belo Horizonte : CEMIG/UFLA/FAEPE, 1995. $28 \mathrm{p}$.

BRASIL. Normais Climatológicas. Ministério da Agricultura e Reforma Agrária. Secretaria Nacional de Irrigação, Departamento Nacional de Meteorologia. Normais Climatológicas - 1960-1991. Brasília, 1992. 84p.

CASTRO, E.M. de et al. Crescimento e distribuição de matéria seca de mudas de calabura (Muntingia calabura L.) submetidas a três diferentes níveis de irradiância. Ciência e Agrotecnologia, Lavras, v.20, n.3, p.357-365, 1996.

CLAUSSEN, J.W. Acclimation abilities of three tropical rainforest seedlings to an increase in light intensity. Forest Ecology and Management, Amsterdam, v.80, n.1/3, p.245255, 1996.

DAVIDE, A.C. et al. Propagação de espécies florestais. Belo Horizonte : CEMIG/UFLA/FAEPE, 1995. 40p.

DIAS-FILHO, M.B. Physiological response of Solanum crinitum Lam. to contrasting light enviroments. Pesquisa Agropecuária Brasileira, Brasília, v.32, n.8, p.789-796, 1997.

ELLSWORTH, D.S.; REICH, P.B. Leaf mass per area, nitrogen content and photosynthetic carbon gain in Acer saccharum seed-lings in contrasting forest light environments. Functional Ecology, Oxford, v.6, p.423-435, 1992.

ENGEL, V.L.; POGGIANI, F. Estudo da concentração de clorofila nas folhas e seu espectro de absorção de luz em função do sombreamento em mudas de quatro espécies florestais nativas. Revista Brasileira de Fisiologia Vegetal, v.3, p.39-45, 1991.

FELFILI, J.M. et al. Comportamento de plântulas de Sclerolobium paniculatum Vog. var. rubiginosum (Tul.) Benth. sob diferentes níveis de sombreamento, em viveiro. Revista Brasileira de Botânica, v.22, n.2, p.297-301, 1999. Suplemento.

GRONINGER, J.W. et al. Growth and photosynthetic responses of four Virginia Piedmont tree species to shade. Tree Physiology, Victoria, v.16, n.9, p.773778,1996 .

KE, G.; WERGER, M.J.A. Different responses to shade of evergreen and deciduous oak seedlings and the effect on acorn size. Acta Oecologica, Berlin, v.20, n.6, p.579$586,1999$.

KÖPPEN, W. Climatología: con un estúdio de los climas de la tierra. Mexico : Fondo de Cultura Economica, 1948. 478p.
KOZLOWSKI, T. et al. The physiological ecology of woody plants. London : Academic, 1991. 657p.

LEE, D.W. et al. Effects of irradiance and spectral quality on leaf structure and function in seedlings of two Southeast Asian Hopea (Dipterocarpaceae) species. American Journal of Botany, Columbus, v.87, n.4, p.447-455, 2000 .

MAZZEI, L.J. et al. Crescimento de plântulas de Schefflera morototoni (Aubl.) Maguire, Steyermark e Frodin em diferentes níveis de sombreamento no viveiro. Boletim do Herbário Ezechias Paulo Heringer, Brasília, v.3, p.27-36, 1998.

MAZZEI, L.J. et al. Crescimento de plântulas de Hymenaea coubaril L. var. stilbocarpa (Hayne) Lee e Lang. em viveiro. Boletim do Herbário Ezechias Paulo Heringer, Brasília, v.4, p.21-29, 1999.

MENDES, M.M. et al. Acclimation of Myrtus communis to contrasting Mediterranean light environments - effects on structure and chemical composition of foliage and plant water relations. Environmental and Experimental Botany, Elmsford, v.45, n.2, p.165-178, 2001.

NAKAZONO, E.M. et al. Crescimento inicial de Euterpe edulis Mart. em diferentes regimes de luz. Revista Brasileira de Botânica v.24, p.173-179. 2001.

OLIVEIRA-FILHO, A.T. et al. Estrutura fitossociológica e variáveis ambientais em um trecho da mata ciliar do córrego Vilas Boas, Reserva Biológica do Poço Bonito, Lavras (MG). Revista Brasileira de Botânica, v.1, n.17, p.67-85, 1994 .

SCALON, S. de P.Q. et al. Crescimento inicial de mudas de espécies florestais nativas sob diferentes níveis de sombreamento. Revista Árvore, v.26, p.1-5, 2002.

SOUSA-SILVA, J.C. et al. Desenvolvimento inicial de Cabralea canjerana Saldanha em diferentes condições de luz. Boletim do Herbário Ezechias Paulo Heringer, Brasília, v.4, p.8089, 1999.

SWAINE, M.; WHITMORE, T.C. On the definition of ecological species groups in tropical rain forests. Vegetatio, The Hague, v.75, p.81-86, 1988.

THOMPSON, W.A. et al. Photosynthetic response to light and nutrients in sun-tolerant and shade-tolerant rainforest trees. I. Growth, leaf anatomy and nutrient content. Australian Journal of Plant Physiology, East Melbourne, v.19, n.1, p.1-18, 1992.

WALTERS, M.B. et al. Growth, biomass distribution and $\mathrm{CO}_{2}$ exchange of northern hardwood seedlings in higt and low light: relationships with successional status and shade tolerance. Oecologia, Berlin, v.94, n.1, p.7-16, 1993.

WELANDER, N.T.; OTTOSSON, B. The influence of low light, drought and fertilization on transpiration and growth in young seedllings of Quercus robur L. Forest Ecology and Management, Amsterdam, v.127, n.1/3, p.139-151, 2000. 